\title{
Clinical and immunological failure among HIV-positive adults taking first-line antiretroviral therapy in Dire Dawa, eastern Ethiopia
}

\author{
Getinet Abera Lenjiso ${ }^{1 *}$ (D) Berhanu Seyoum Endale ${ }^{2,4}$ and Yadeta Dessie Bacha ${ }^{3}$
}

\begin{abstract}
Background: Access to antiretroviral therapy (ART) in Ethiopia has been scaled up since the introduction of the service in 2003. Free ART was launched in 2005, resulting in fewer new human immunodeficiency virus (HIV) infections and deaths from acquired immunodeficiency syndrome (AIDS). However, immunological and clinical failures for first-line ART due to poor adherence and other factors have received less attention. Thus, this study aims to determine the magnitude and associated factors of clinical and immunological failure among HIV-positive adults after six months of first-line ART in Dire Dawa, Eastern Ethiopia.

Methods: A facility-based cross-sectional study was conducted using secondary data of patients on ART in all health facilities providing ART services in Dire Dawa. A total of 949 samples were collected. The data were entered into Epidata version 3.02, and the analysis was performed using SPSS version 16.0. Univariate and multivariate analyses were performed to determine the magnitude of clinical and immunological failure and identify factors significantly associated with the outcome variable.

Results: The magnitude of clinical and immunological failure was $22.7 \%(n=215)$. Of these, $33(15 \%)$ patients were switched to second-line ART. CD4 count $\leq 100$ cells/mm3 (AOR: 1.78, 95\% Cl: 1.18-2.69), poor adherence (AOR: 2.5, 95\% Cl: 1.19-5.25), restarting after interruption of ART (AOR: 1.93, 95\% Cl: 1.23-3.07), regimen change (AOR: 1.50, 95\% Cl: 1.05-2.15), ambulatory/bedridden functional status at the last visit on ART (AOR: $2.41,95 \%$ Cl: 1.22-4.75) and patients who died (AOR: 3.94, 95\% Cl: 1.64-9.45) had higher odds of failure.

Conclusion: The magnitude of clinical and immunological failure was high. To curb this problem, initiation of ART before the occurrence of severe immune suppression, early detection and management of failure and improved adherence support mechanisms are recommended. Restarting treatment after interruption and regimen changesshould-be-made-cautiously.
\end{abstract}

Keywords: Clinical failure, Immunological failure, Adherence, Functional status

\footnotetext{
* Correspondence: aberagetinet@yahoo.com

'Disease Prevention and Control Case Team, Dire Dawa Administration

Health Bureau, P.O Box 1377, Dire Dawa, Ethiopia

Full list of author information is available at the end of the article
}

(c) The Author(s). 2019 Open Access This article is distributed under the terms of the Creative Commons Attribution 4.0 International License (http://creativecommons.org/licenses/by/4.0/), which permits unrestricted use, distribution, and reproduction in any medium, provided you give appropriate credit to the original author(s) and the source, provide a link to the Creative Commons license, and indicate if changes were made. The Creative Commons Public Domain Dedication waiver (http://creativecommons.org/publicdomain/zero/1.0/) applies to the data made available in this article, unless otherwise stated. 


\section{Background}

At the beginning of the AIDS pandemic, treatment was confined to palliative care and management of opportunistic infections (OIs). The advent of ART has made HIV a manageable chronic illness; however, there is still no cure [1]. From 1995 to 2010, ART has saved 14 million life years in low- and middle-income countries, including 9 million in sub-Saharan Africa (SSA) [2].

In Ethiopia, national guidelines on the use of antiretroviral drugs (ARVs) were developed, and the ART program was launched in 2003. Subsequently, in 2005, a free ART program was initiated in three government hospitals in Addis Ababa. Since then, the geographic distribution and number of centers with ART services have increased to 743 health facilities in 2010/11 [3]. A 53\% decline in AIDSrelated death has been reported between 2005 and 2011 [2].

The primary goals of HIV treatment include suppression of viral replication, restoration of the immune response, a halt in the progression of disease, increased survival rates, reduced morbidity, and a better quality of life [4]. For ART, a high level of sustained adherence is necessary to suppress viral replication and improve immunological and clinical outcomes, decrease the risk of developing ARV drug resistance, and reduce the risk of transmitting HIV [5]. Failure to reduce the viral load can lead to the evolution of drug resistance, with subsequent immunological and clinical failures [6].

Although estimates suggest that only $2 \%$ of those currently on ART are on a second-line regimen worldwide, a far greater number are likely to be failing virologically but have not switched from first-line therapy [7]. The world health organization (WHO) estimated that close to 500,000 to 800,000 patients required switching to secondline regimens by 2010 [8].

Identifying patients failing on first-line treatment is a major challenge in ART programs in resource-limited settings. As a result, patients who are failing on a first-line regimen are often not switched to a second-line regimen in a timely manner [9]. This leads to high morbidity and mortality among patients who fail on first-line ART $[9,10]$.

The time of switching is dictated by treatment failure, and this can be measured in three ways: clinically, immunologically, and virologically. Viral load monitoring is the gold standard method to diagnose ART failure [9]. The sensitivity and specificity of the WHO-based clinical and immunological failure algorithm were 31 and $87 \%$, respectively, which would result in $14 \%$ of those with viral suppression being switched inappropriately to second-line ART [11]. However, due to the lack of access to viral load determination in Ethiopia, the diagnosis of treatment failure has been mainly performed by clinical and immunological assessment methods before 2017. To substantially increase the success rate of ART, there is a need to know the magnitude of clinical and immunological failure for first-line ART and to better understand the factors associated with it.

Monitoring for early warning signs of failure should be intensified to prevent resistance to ARVs, one of which is through the identification of clinical and/or immunological failure, which are surrogate markers to the presence of virological failure [12]. Different studies describing the prevalence and predictors of immunological and virological failures have been conducted in different countries. However, there is scarcity of data in Ethiopia in general and in our study area in particular. A single study conducted in Ethiopia showed a $21 \%$ prevalence of immunological failure [13]. Therefore, the present study was conducted to determine the magnitude of clinical and immunological failure and associated factors among HIV-positive adults after six months of first-line ART in Dire Dawa, Eastern Ethiopia.

\section{Methods}

\section{Study area}

The study was conducted in Dire Dawa administration, which is located in the eastern part of Ethiopia $515 \mathrm{~km}$ away from Addis Ababa. Thirteen health facilities, including 9 health centers and 4 hospitals, provide ART services. As per the regional health bureau report at the end of August 2013, a total of 7569 clients had been started on ART. The proportion of patients who had ever been started on ART at a public hospital, 9 health centers, and 3 private hospitals were 61, 29 and 10\%, respectively. The procedure of enrollment in chronic HIV care in the administration was that patients who tested positive for HIV at different service outlets were enrolled in HIV care and registered as pre-ART. The medical eligibility criteria for ART initiation and preferred first-line regimens were as per the national guideline [14].

\section{Study design}

Health facility-based cross-sectional study design using secondary data was used. The study was conducted in all ART providing health facilities in Dire Dawa, Eastern Ethiopia, from January 1 to 30, 2014. Out of the total 7569 people living with HIV (PLHIV) who were put on treatment at the time of the study, 7306 of them were adults and adolescents above the age of 14 years.

The study population was HIV-positive adults and adolescents (age $\geq 15$ years) who started on ART in the study area and took ART for more than 6 months. The records of all HIV-positive adults and adolescents who were taking ART for more than 6 months from the facility they started the treatment between December 2003 and January 2013 were included in the study.

\section{Measurements}

The dependent variable was clinical and/or immunological failure among HIV-positive adults and adolescents on the first-line ART 6 months after ART initiation. Clinical 
failure is the occurrence of new or recurrent WHO stage IV condition 6 months after ART initiation. Immunological failure occurs when there is a fall of $\mathrm{CD} 4$ counts to pretherapy baseline (or below) or 50\% fall from the on-treatment peak value (if known) or persistent CD4 levels below 100 cells $/ \mathrm{mm}^{3} 6$ months after ART initiation $[14,15]$. The independent variables were sociodemographic characteristics, disclosure, duration on ART, eligibility criteria for ART initiation, CD4 level, WHO clinical staging, functional status, history of tuberculosis (TB), type of ARV regimens, history of treatment interruption, prior exposure to ARVs, substitution of first-line ART, switch to second-line ART, adherence, outcome of care, etc.

\section{Sample size and sampling techniques}

The sample size was calculated using a single population proportion formula considering 95\% significance level, $21 \%$ magnitude of treatment failure [13], 2.5\% degree of precision, and $10 \%$ nonresponse rate considering for compensation of incomplete records. The final sample size calculated was 989 . Based on this sample size, all health facilities providing ART service were included, and the sample size was proportionally allocated to each facility based on the patient load the health facilities had. The sampling frame was that the list of all patient records in the specified period was obtained from the patient registers and electronic databases in all the health facilities. The lists of patients were then stratified based on the duration after ART initiation in each health facility, and the final sampling frame was prepared. Stratified proportionate sampling with a systematic random sampling method was then used to obtain the samples.

\section{Data collection}

Data collection was carried out using a pretested structured data extraction tool. Pretesting of the data extraction tool was conducted on $5 \%$ of the sample size in a hospital outside the study area. The data extraction tool was developed from the data elements on the nationally standardized HIV patient intake and follow-up formats, which are prepared based on the WHO patient monitoring guidelines [16]. The data were collected by 12 data collectors who had a minimum diploma in information and communication technology (ICT). After obtaining permission from the medical directors, all the data were collected from the individual patient chart after the data extraction tool was provided to the data collectors and charts brought to them from the medical record units. Three supervisors were involved with the responsibility to collect the data extraction tools every day after checking the completeness and consistency. The data collectors were trained in ART data management and familiar with all the information in the data extraction instrument. Orientation was also given to the data collectors and supervisors. The collected data were reviewed after the initial data entry and after the final SPSS data file was created.

\section{Statistical analysis}

The collected data were entered into Epi-data version 3.02 and exported to SPSS version 16.0 for cleaning and analysis. Univariate analysis was used to determine the magnitude of treatment failure and describe the data. Bivariate analysis was performed to estimate the magnitude of the association with treatment failure. A binary logistic regression model was used to identify covariates that were associated with the outcome variable (treatment failure). Factors that were marginally associated at the $p$-value < 0.10 in the bivariate analysis were included in the multivariable model. A significance level of 0.05 was used to guide the interpretation of relationships in the final multivariable model calculating AOR and 95\% CIs. Variables with more than $10 \%$ missing values due to incomplete recording on patient charts were excluded from the analysis.

Ethical clearance was obtained from the Institutional Research Ethics Review Committee of Haramaya University, College of Health and Medical Sciences. Support letter was obtained from the Dire Dawa administration health bureau. Informed consent from the health facilities medical directors was also obtained. The information was kept confidential and anonymous.

\section{Results}

\section{Sociodemographic characteristics}

A total of 949 study participants were included. The majority of the respondents (63\%) were females. The median age of the patients at the start of ART was 32 years (IQR: 28-40). Nearly all (95\%) of the patients resided in Dire Dawa town. Four hundred two of the patients $(43 \%)$ were married or cohabitating. The majority of the patients (65\%) were Orthodox Christians by religion. Four hundred twelve (44\%) of the patients had a primary level of education. Nearly two out of three (65\%) patients were unemployed at the time of enrollment in chronic HIV care. Six hundred fifty-eight (69\%) of the patients disclosed their HIV status to someone they had a close relationship with. The distribution of survey patients across the health facility type showed that the majority of the study subjects (60\%) were from the public hospital, 288 (30\%) were from health centers, and 98 (10\%) were from private hospitals (Table 1).

\section{Clinical characteristics of the study subjects}

Only a few $(2 \%)$ of the patients in the survey had a history of prior exposure to ARVs. Baseline CD4 was determined for $97 \%$ of the patients, of whom the majority (69\%) had a CD4 count $>100$ cells $/ \mathrm{cm}^{3}$ with a median count of 150 cells $/ \mathrm{cm}^{3}$ (IQR: 83-222). Nearly half (46\%) 
Table 1 Sociodemographic characteristics of the study subjects in Dire Dawa, Eastern Ethiopia, January 2014

\begin{tabular}{|c|c|c|}
\hline Sociodemographic characteristics & Frequency & Percent (\%) \\
\hline \multicolumn{3}{|l|}{ Sex } \\
\hline Male & 352 & 37 \\
\hline Female & 597 & 63 \\
\hline \multicolumn{3}{|l|}{ Age (in years) } \\
\hline $15-24$ & 108 & 11 \\
\hline $25-34$ & 402 & 42 \\
\hline $35-44$ & 281 & 30 \\
\hline $45-54$ & 120 & 13 \\
\hline $55^{+}$ & 38 & 4 \\
\hline \multicolumn{3}{|l|}{ Median age 32 (IQR: 28-40) } \\
\hline \multicolumn{3}{|l|}{ Place of residence } \\
\hline Dire Dawa & 902 & 95 \\
\hline Outside of Dire Dawa & 47 & 5 \\
\hline \multicolumn{3}{|l|}{ Marital Status $(n=937)$} \\
\hline Never married & 157 & 17 \\
\hline Married or cohabitating & 402 & 43 \\
\hline Divorced or separated & 239 & 26 \\
\hline Widowed/er & 139 & 15 \\
\hline \multicolumn{3}{|l|}{ Religion ( $n=939$ ) } \\
\hline Orthodox & 614 & 65 \\
\hline Muslim & 244 & 26 \\
\hline Others $^{*}$ & 81 & 9 \\
\hline \multicolumn{3}{|l|}{ Educational status ( $n=934$ ) } \\
\hline No formal education & 210 & 22 \\
\hline Primary & 412 & 44 \\
\hline Secondary & 258 & 28 \\
\hline Tertiary & 54 & 6 \\
\hline \multicolumn{3}{|l|}{ Employment $(n=855)$} \\
\hline Employed & 266 & 31 \\
\hline Unemployed & 557 & 65 \\
\hline Not working due to ill health & 32 & 4 \\
\hline \multicolumn{3}{|l|}{$\begin{array}{l}\text { Disclosure status during enrollment } \\
(n=948)\end{array}$} \\
\hline Disclosed & 658 & 69 \\
\hline Not disclosed & 290 & 31 \\
\hline \multicolumn{3}{|l|}{ Type of health facility } \\
\hline Public hospital & 563 & 60 \\
\hline Health center & 288 & 30 \\
\hline Private hospital & 98 & 10 \\
\hline
\end{tabular}

"Others include Protestant and Catholic religions

of the patients started ART based on combined clinical and immunological eligibility criteria. Nucleoside reverse transcriptase inhibitors (NRTIs) containing stavudine and non-nucleoside reverse transcriptase inhibitors
(NNRTIs) containing neverapine-based first-line ART were initiated for 528 (56\%) and 563 (59\%) of the patients, respectively. Restarting first-line ART after interruptions was observed in $140(15 \%)$ of the patients. Poor adherences were recorded in $46(5 \%)$ patients at the time of their least CD4 count record during the course of ART. Almost half (51\%) of the patients had a history of regimen change due to toxicity, pregnancy, tuberculosis, etc. Nearly $40 \%$ of the patients $(n=387)$ had been on ART for more than 4 years, with a mean ART duration of 44 months (SD: \pm 26 ). Six hundred (60\%) of the patients were alive and taking their ART. The majority of the patients $(62 \%, n=594)$ were at WHO clinical stage III/IV conditions at the time of entry to chronic HIV care, and the percentage was even higher $(71 \%, n=675)$ at the time of ART initiation (Table 2).

\section{Magnitude of clinical and immunological failure}

The magnitude of clinical and immunological failure while on first-line ART was $22.7 \%$ (95\% CI: $20.0-25.4, n=215$ ). Stratifying by the type of failure, immunological failure alone was $19.3 \%$ (Fig. 1). Only 33 (15\%) of the study subjects with failure status were switched to second-line ART.

Ninety-six (45\%) of the failures had occurred within 6 to 12 months of ART initiation, and almost $69 \%$ of the failures occurred within 6 to 24 months of ART initiation (Fig. 2). The median time for the occurrence of the failure was 14 months (IQR: 8-31).

\section{Clinical characteristics associated with clinical and immunological failure}

The odds of clinical and immunological failure was 1.78 times $(\mathrm{AOR}=1.78,95 \% \mathrm{CI}: 1.18-2.69)$ higher among study subjects with a baseline CD4 count $\leq 100$ cells $/ \mathrm{cm}^{3}$ compared to those with CD4 count $>100$ cells $/ \mathrm{cm}^{3}$. Poor adherence was associated with a higher odds of clinical and immunological failure (AOR: 2.5, 95\% CI: 1.19-5.25). Similarly, ambulatory or bedridden functional status at the last follow-up visit on ART was associated with higher odds of clinical and immunological failure (AOR: 2.41; 95\% CI: 1.12-4.75) (Table 3).

The presence of restarting treatment after interrupting ART had a 1.93 times (AOR $=1.93,95 \%$ CI: $1.23-3.07)$ higher odds of clinical and immunological failure compared to those with no similar history. Among study subjects with a history of substitution or change in their first-line ART regimen, the odds of clinical and immunological failure was 1.5 times $(\mathrm{AOR}=1.5,95 \% \mathrm{CI}$ : $1.05-2.15)$ higher than those who had no similar history. Compared to study subjects who were alive and on ART, the odds of treatment failure among those who died were almost 4 times (AOR: 3.94, 95\% CI: 1.64-9.45) higher (Table 3). 
Table 2 Clinical characteristics of the study subjects at enrollment to chronic HIV care, initiation of ART, and during follow-up in Dire Dawa, Eastern Ethiopia, January 2014

Clinical characteristics
History of exposure to ARVs before
initiation of ART
initiation of ART

Present

Absent

Eligibility criteria for ART initiation

Clinical only

CD4 only

Both clinical \& CD4

$\mathrm{TLC}^{*}$ \& other

Baseline CD4 ( $n=923)$

CD4 $>100$ cells $/ \mathrm{cm}^{3}$

CD4 $\leq 100$ cells $/ \mathrm{cm}^{3}$

Median CD4 count $=150($ IQR: 83-222)

NNRTI-based first-line ART initiated to patients

Nevirapine based

Efavirenz based

NRTI-based first-line ART initiated to patients

\section{Tenofovir based \\ Zidovudine based}

Stavudine based

Adherence when least CD4 recorded $(\mathrm{n}=907)$

Good (> = 95\%)

Poor (<95\%)

ART interruption and restart history

Absent

Present

History of regimen change $(n=916)$

Absent

Present

Duration on ART

6-24 months

24-48 months

$\geq 48$ months

Mean duration $=44$ months SD: \pm 26

Status of the patient at the time of the survey

Alive and on ART
Transfer out
Lost/drop out
Dead

WHO clinical staging at enrollment to pre-ART
Table 2 Clinical characteristics of the study subjects at enrollment to chronic HIV care, initiation of ART, and during follow-up in Dire Dawa, Eastern Ethiopia, January 2014 (Continued)

\begin{tabular}{lll}
\hline Clinical characteristics & Frequency & Percent (\%) \\
\hline Stage I/II & 355 & 38 \\
Stage III/IV & 594 & 62 \\
WHO clinical staging at ART initiation & & \\
Stage I/II & 274 & 29 \\
Stage III/IV & 675 & 71 \\
\hline
\end{tabular}

${ }^{*} T L C$ - total lymphocyte count

\section{Discussion}

In this study, the magnitude of clinical and immunological failure was $22.7 \%$, with only immunological, only clinical, and both clinical and immunological failures constituting 19.3, 2, and 1.4\%, respectively. This magnitude is almost equivalent to the magnitude of failure reported in the Ethiopian study, which is $21 \%$ [13]. It is higher than the magnitude reported in the study conducted in Lesotho, South Africa, where the magnitude was $11.8 \%$ [17]. It is lower than the magnitude reported in India (26.1\%) and Malawi $(48 \%)[18,19]$. Based on the reviewed literature in this study, a very high magnitude of treatment failure is reported from the study in Malawi, but the immunological failure criteria of CD4 drop of $30 \%$ from the peak are used. This study used a CD4 count drop of $50 \%$ from the peak value as one of the criteria for immunological failure. Other studies also report that with global access to ART increases, it is expected that at least $5-20 \%$ of patients will have their first line regimens fail before 4 years of therapy despite adequate adherence, plasma drug levels, and treatment efficacy $[20,21]$. This research identifies the median time from the initiation of ART until the occurrence of clinical and immunological failure to be 14 months (IQR: $8-31$ ) and $45 \%$ of failures occurring between 6 and 12 months of ART initiation. This finding is less than the finding reported in Ethiopia, where 57.9\% of failures occurred during the same period [13]. Another study conducted in Kenya also reported the median time to ART failure to be 37 months (IQR: 15-27) [22]. The Tanzanian cross-sectional study reports 20 months (IQR: 1527) to be the mean durability of the first-line regimen before failure occurs [23]. The variability in the median time for the occurrence of failure might be explained by the difference in the socioeconomic status between the study areas. The short duration for the occurrence of treatment failure identified in this study goes with the EuroSIDA study that showed a gradual and significant decline in the rate of immunological failure over time [24]. The early occurrence of clinical and immunological failure in this study might be explained by the fact that 


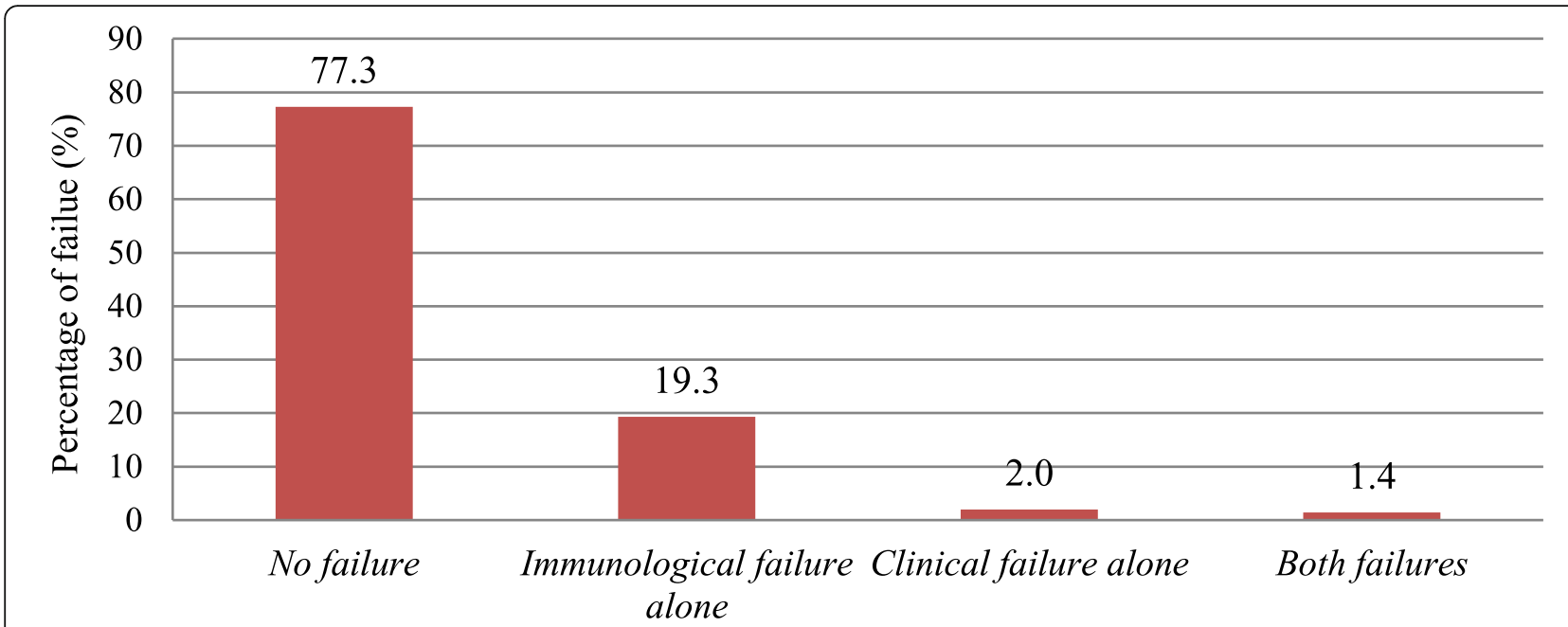

Fig. 1 Diagrammatic presentation of the occurrence of clinical and immunological failure among the study subjects in Dire Dawa, Eastern Ethiopia, January 2014

patients are enrolled in care with severe immune suppression and problem in adherence, as shown in the factor analysis. As indicated in Table 2, the median baseline CD4 count in this study is 150 cells $/ \mathrm{mm}^{3}$ compared to the baseline CD4 count of 200 cells $/ \mathrm{mm}^{3}$ in the EuroSIDA study [24].

Among patients identified as failure, only 15\% were switched to second-line ART. This is far less than the record in the Tanzania study, where $41 \%$ of failed patients initiated second-line ART [23]. This might show that patients who are failing on the first-line regimen are not switched in a timely manner to the second-line regimen. Studies have shown that putting patients on a failing first-line regimen leads to high morbidity and mortality $[10,25,26]$. An indication of this fact in this study is that among study subjects who died and had clinical and immunological failure, only
$6.7 \%$ of them were switched to second-line ART, and patients who died were 4 times (AOR: 3.9495, 95\% CI: $1.64-$ 9.45) more likely to have clinical and immunological failure compared to those who were alive and on treatment at the time of the study. This might be due to the reduced attention given to diagnosing failure early, lack of trained manpower to pick and manage treatment failures early, and lack of early and accurate diagnostic setup. Early initiation of a second-line regimen after the diagnosis of failure is a key for the reduction of morbidity and mortality associated with taking a failing regimen [15].

This research identifies that patients with a baseline CD4 count of $\leq 100$ cells $/ \mathrm{mm}^{3}$ have 1.78 (95\% CI: $1.18-2.69$ ) times higher odds of clinical and immunological failure compared to patients with a CD4 count greater than 100 cells $/ \mathrm{mm} 3$. Similar findings are observed in the studies

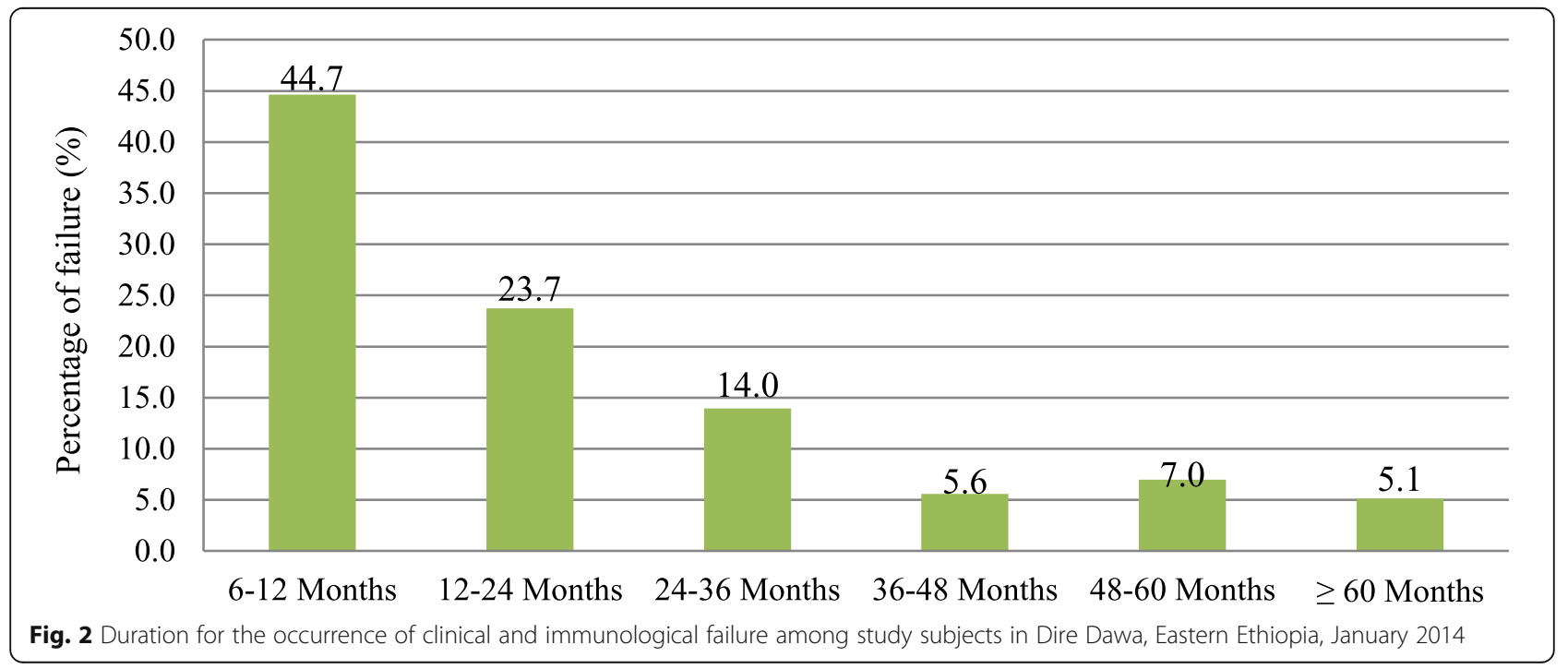


Table 3 Multivariate analysis of clinical characteristics associated with clinical and immunological failure in Dire Dawa, Eastern Ethiopia, January 2014

\begin{tabular}{|c|c|c|c|c|}
\hline Factors & Failure (\%) & No failure (\%) & Unadjusted OR (95\% Cl) & Adjusted OR $(95 \% \mathrm{Cl})$ \\
\hline \multicolumn{5}{|l|}{ Baseline CD4 $(n=923)$} \\
\hline CD4 > 100 cells $/ \mathrm{cm}^{3}$ & $125(19.5)$ & $516(80.5)$ & 1 & 1 \\
\hline CD4 $\leq 100$ cells $/ \mathrm{cm}^{3}$ & $85(30.2)$ & $197(69.8)$ & $1.78(1.29-2.45)$ & $1.78(1.18-2.69)^{*}$ \\
\hline \multicolumn{5}{|c|}{$\begin{array}{l}\text { WHO clinical stage when ART } \\
\text { initiated }(n=949)\end{array}$} \\
\hline Stage $|/| \mid$ & $49(17.9)$ & $225(82.1)$ & 1 & 1 \\
\hline Stage II/IV & $166(24.6)$ & $509(75.4)$ & $1.50(1.05-2.13)$ & $0.39(0.11-1.37)$ \\
\hline \multicolumn{5}{|c|}{$\begin{array}{l}\text { NRTI-based first-line ART initiated } \\
\text { to patients }(n=949)\end{array}$} \\
\hline TDF based & $51(17.9)$ & $234(82.1)$ & 1 & 1 \\
\hline ZDV based & $30(22.1)$ & $106(77.9)$ & $1.29(0.78-2.18)$ & $1.08(0.42-2.79)$ \\
\hline D4T based & $134(25.4)$ & $394(74.6)$ & $1.56(1.09-2.24)$ & $1.19(0.47-3.05)$ \\
\hline \multicolumn{5}{|c|}{ Type of health facility $(n=949)$} \\
\hline Health center & $51(17.7)$ & $237(82.3)$ & 1 & 1 \\
\hline Public hospital & $141(25.0)$ & $422(75.0)$ & $1.55(1.09-2.22)$ & $1.21(0.64-2.28)$ \\
\hline Private hospital & 23(23.5) & $75(76.5)$ & $1.42(0.82-2.49)$ & $0.94(0.33-2.65)$ \\
\hline \multicolumn{5}{|c|}{ Adherence at the least CD4 $(n=907)$} \\
\hline Good (> = 95\%) & $188(21.8)$ & $673(78.2)$ & 1 & 1 \\
\hline Poor $(<95 \%)$ & $25(54.4)$ & 21(45.6) & $4.26(2.33-7.78)$ & $2.50(1.19-5.25)^{*}$ \\
\hline \multicolumn{5}{|c|}{$\begin{array}{l}\text { Functional status of the patient at } \\
\text { last visit on ART }(n=949)\end{array}$} \\
\hline Working & $185(20.8)$ & $703(79.2)$ & 1 & 1 \\
\hline Ambulatory/bedridden & $30(49.2)$ & $31(50.8)$ & $3.68(2.17-6.23)$ & $2.41(1.22-4.75)^{*}$ \\
\hline \multicolumn{5}{|c|}{$\begin{array}{l}\text { History of TB treatment while on } \\
\text { ART }(n=949)\end{array}$} \\
\hline Absent & $171(27.7)$ & $655(72.3)$ & 1 & 1 \\
\hline Present & $44(35.8)$ & $79(64.2)$ & $2.13(1.42-3.20)$ & $1.57(0.96-2.55)$ \\
\hline \multicolumn{5}{|c|}{ ART interruption history $(n=949)$} \\
\hline Absent & $157(20.1)$ & $652(79.9)$ & 1 & 1 \\
\hline Present & $58(41.4)$ & $82(58.6)$ & $2.94(2.01-4.29)$ & $1.93(1.23-3.07)^{*}$ \\
\hline \multicolumn{5}{|c|}{ History of regimen change $(n=916)$} \\
\hline Absent & $75(16.0)$ & $394(84.0)$ & 1 & 1 \\
\hline Present & $107(23.9)$ & $340(76.1)$ & $1.65(1.19-2.29)$ & $1.50(1.05-2.15)^{*}$ \\
\hline \multicolumn{5}{|c|}{ Duration on ART $(n=949)$} \\
\hline $6-24$ months & $51(18.0)$ & $233(82.0)$ & 1 & 1 \\
\hline 24-48 months & $63(22.7)$ & $215(77.3)$ & $1.34(0.89-2.02)$ & $1.44(0.87-2.38)$ \\
\hline$\geq 48$ months & $101(26.1)$ & $286(73.9)$ & $1.61(1.10-2.35)$ & $1.42(0.79-2.54)$ \\
\hline \multicolumn{5}{|c|}{$\begin{array}{l}\text { Status of the patient at the time of } \\
\text { the survey }(n=949)\end{array}$} \\
\hline Alive on ART & $170(28.3)$ & $430(71.7)$ & 1 & 1 \\
\hline Lost/dropped out & $34(29.8)$ & $80(70.2)$ & $1.54(0.98-2.40)$ & $1.37(0.78-2.40)$ \\
\hline Transferred out & $36(17.5)$ & $170(82.5)$ & $0.77(0.51-1.15)$ & $0.99(0.63-1.55)$ \\
\hline Died & $15(51.7)$ & $14(48.3)$ & 3.87 (1.82-8.23) & $3.94(1.64-9.45)^{*}$ \\
\hline
\end{tabular}

NB: ${ }^{*}=P<0.05$ and variables that fit in the final model 
conducted in Ethiopia and Tanzania [13, 23]. The report in the Kenyan study showed a CD4 count of $<50$ cells/mm3 to be a significant predictor for treatment failure [22]. This finding might be because patients with a baseline CD4 count of $\leq 100$ cells $/ \mathrm{mm} 3$ have reduced immunity, and the response to the first-line ART may be unsatisfactory.

This study shows that poor adherence is independently associated with clinical and immunological failure (AOR: 2.5; 95\% CI: 1.19-5.25). This is similar to findings from the report in the Kenya study, which showed imperfect adherence to be an independently associated factor for treatment failure (AOR: 2.77; 95\% CI: 2.20-3.49) [22]. Other studies also show similar findings $[23,27,28]$. Adherence to ART is needed to ensure optimal benefit from the ARVs [29]. Treatment interruption and restarting the first-line ART again is also a form of non-adherence, and this research study found that patients with a history of restarting treatment after interruption have a 1.5 times (AOR: 1.93, 95\% CI: 1.23-3.07) higher odds of clinical and immunological failure than those who never had a similar history. Even if the criteria for failure are different from this study, treatment interruption is reported to be a significant predictor of virological failure in the Gabon study [30]. A study in Uganda also reported that ARV resistance was reported in patients who interrupted their therapy [31].

The functional status of the patient at their last followup visits was assessed, and the finding showed that patients who were "ambulatory or bedridden" had a 2.4 times (AOR: 2.41, 95\% CI: 1.22-4.75) higher odds of clinical and immunological failure. This might be due to the higher rate of morbidity associated with the inability to identify failures early and switch to a second-line regimen, resulting in the occurrence of different opportunistic infections and other diseases, which in turn leads to impaired functional status. Baseline functional status shows no significant associations, which is similar to the report in the Ethiopian study [13].

Regimen change/substitution of the original first-line ART to an alternative first-line ART for different reasons is associated with a 1.5 times (AOR: $1.50,95 \%$ CI: $1.05-$ 2.15) higher odds of clinical and immunological failure compared to those with no history of regimen change. The EuroSIDA study reports that a substitution to the ART regimen showed marginal statistical significance (AHR: 1.21, 95\% CI: 0.98-1.48) [24]. This finding might show the presence of substitution of first-line ART regimens, which may lead to the occurrence of resistance and an increasing chance of treatment failure.

\section{Limitation of the study}

The study uses secondary data collected retrospectively resulting in incompleteness of clinical data, and hence, information bias may have occurred because of underreporting/missing data elements. The magnitude of clinical and immunological failure could be overestimated as no confirmatory virological tests were performed to confirm the failure because the use of immunological and clinical failure criteria lacks both sensitivity and specificity to detect failure.

\section{Conclusion}

There was a high magnitude of clinical and immunological failure. Nearly half of the failures occurred during the first 12 months of ART initiation. Switching to second-line ART was low. A very low baseline CD4 count was associated with a high occurrence of failure. Higher odds of failures were also observed in patients with poor adherence. Interrupting and restarting of the first-line ART were associated with higher odds of failure. Substituting/changing a first-line regimen with an alternative first-line regimen was also a factor associated with a high occurrence of clinical and immunological failure. The presence of ambulatory or bedridden functional status at the last follow-up visit on ART might show that there was a significant level of morbidity due to clinical and immunological failure. Failure was also present significantly among patients who died, showing the high magnitude of mortality associated with the use of probably a failing first-line ART.

Early diagnosis of HIV-positive status, early enrollment in chronic HIV care, and initiation of ART before the occurrence of severe immune suppression should be promoted. Early recognition and management of clinical and immunological failure should be given due attention. Efforts to improve adherence to therapy should be strengthened. Regimen change or substitution to the original first-line ART regimen should be made cautiously. Despite some limitations, this study is a major step forward for the regional and national HIV program and should serve as an impetus for further studies using primary data in this area.

\section{Abbreviations \\ AHR: Adjusted Hazard Ratio; AIDS: Acquired Immunodeficiency Syndrome; AOR: Adjusted Odds Ratio; ART: Antiretroviral Therapy; ARVs: Antiretroviral drugs; Cl: Confidence Interval; FHAPCO: Federal HIV/AIDS Prevention and Control Office; FMoH: Federal Ministry of Health; HIV: Human \\ Immunodeficiency Virus; ICT: Information Communication Technology; IQR: Inter Quartile Range; NNRTI: Non-Nucleoside Reverse Transcriptase Inhibitor; NRTI: Nucleoside Reverse Transcriptase Inhibitor; Ols: Opportunistic Infections; PI: Protease Inhibitor; PLHIV: People Living with HIV; \\ SPSS: Statistical Package for the Social Sciences; SSA: Sub-Sahara Africa; TB: Tuberculosis; UNAIDS: The United Nations Joint Program on HIV/AIDS; UNICEF: United Nations International Children's Emergency Fund; WHO: World Health Organization}

\section{Acknowledgments}

We would like to thank Haramaya University, College of Health and Medical Sciences, the Dire Dawa administration health bureau and the health facilities that provided ART in Dire Dawa for their cooperation and permission to conduct the study. We are also very grateful for the support and commitment of the data collectors and supervisors who participated in this study. 


\section{Authors' contributions}

GAL was involved in the conception of the work, design, analysis, write-up and approval for publication. BSE and YDB were involved in critically revising the work starting from the design, analysis, and write-up with approval for publication. GAL takes responsibility for the paper as a whole. All authors have read and approved the manuscript.

\section{Funding}

Not applicable.

\section{Availability of data and materials}

The datasets (SPSS) used and analyzed during the current study are available from the corresponding author on reasonable request.

\section{Ethics approval and consent to participate}

Ethical clearance was obtained from the Institutional Research Ethics Review Committee of Haramaya University, College of Health and Medical Sciences. Support letter was obtained from the Dire Dawa administration health bureau. Informed written consent from the health facilities medical directors was also obtained. The information was kept confidential and anonymous.

\section{Consent for publication}

Not applicable.

\section{Competing interests}

The authors declare that they have no competing interests.

\section{Author details}

'Disease Prevention and Control Case Team, Dire Dawa Administration Health Bureau, P.O Box 1377, Dire Dawa, Ethiopia. ${ }^{2}$ Department of Medical Laboratory Science, Haramaya University Colleges of Health and Medical Sciences, Harar, Ethiopia. ${ }^{3}$ School of Public Health, Haramaya University Colleges of Health and Medical Sciences, Harar, Ethiopia. ${ }^{4}$ Armauer Hansen Research Institute, Addis Ababa, Ethiopia.

Received: 17 October 2018 Accepted: 30 May 2019

Published online: 17 June 2019

\section{References}

1. UNAIDS. World AIDS day report. Geneva, Switzerland: UNAIDS; 2011. Available from: https://www.unaids.org/sites/default/files/media_asset/ JC2216_WorldAIDSday_report_2011_en_1.pdf. Accessed 21 Oct 2018.

2. World Health Organization, UNAIDS, UNICEF. Global HIV/AIDS response: Epidemic update and health sector progress towards universal access. Progress report. Geneva, Switzerland: WHO; 2011. Available from: https:/apps.who.int/ iris/bitstream/handle/10665/44787/9789241502986_eng.pdf?sequence=1. Accessed 21 Oct 2018.

3. FHAPCO. Country progress report on HIV/AIDS response. Addis Ababa Ethiopia: FHAPCO; 2012. Available from: http://s3.amazonaws.com/zanran_ storage/www.unaids.org/ContentPages/2546109285.pdf. Accessed 21 Oct 2018.

4. WHO. Antiretroviral therapy for HIV infection in adults and adolescents in resource limited settings: towards universal access. Recommendations for a public health approach. Geneva, Switzerland: WHO; 2006. Available from: https://apps.who.int/iris/bitstream/handle/10665/43554/9789241594677_ eng.pdf? sequence=1\&isAllowed=y. Accessed 21 Oct 2018.

5. FMoH. National Guidelines for Comprehensive HIV Prevention, Care and Treatment in Ethiopia. Addis Ababa, Ethiopia: FMoH; 2014. Available from: https://aidsfree.usaid.gov/sites/default/files/ethiopia_natl_gl_2014.pdf. Accessed 18 Sep 2018.

6. WHO. The use of antiretroviral therapy; a simplified approach for resource constrained countries. Geneva, WHO; 2002. Available from: https://pdfs. semanticscholar.org/1d6b/47a6926ced9e07631b16df31a69e0e8f23a2.pdf. Accessed 21 Oct 2018

7. WHO, UNICEF. Towards universal access: scaling up priority HIV/AIDS interventions in the health sector. Geneva, Switzerland: World Health Organization; 2009. Available from: https://www.who.int/hiv/pub/tuapr_ 2009 en.pdf?ua=1. Accessed 21 Oct 2018.

8. Boyd MA. Current and future management of treatment failure in low and middle-income countries. Curr Opin HIV AIDS. 2010;5(1):83-9. Available from. https://doi.org/10.1097/COH.0b013e328333b8c0.
9. Keiser O, Tweya H, Braitstein P, Dabis F, MacPhail P, Boulle A, Nash D, Wood R, Lüthi R, Brinkhof MWG, Schechter M, Egger M. Mortality after failure of antiretroviral therapy in sub-Saharan Africa. Tropical Med Int Health. 2010; 15(2):251-8. Available from. https://doi.org/10.1111/j.1365-3156.2009.02445.x.

10. Pujades-Rodriguez M, Balkan S, Arnould L, Brinkhof MA, Calmy A, AIDS working group of MSF. Treatment failure and mortality factors in patients receiving second-line HIV therapy in resource-limited countries. JAMA. 2010; 304:303-12.

11. Meya D, Spacek LA, Tibenderana H, John L, Namugga I, Magero S, Dewar R, Quinn TC, Colebunders R, Kambugu A, Reynolds SJ. Development and evaluation of a clinical algorithm to monitor patients on antiretroviral in resource-limited settings using adherence, clinical and CD4 cell count criteria. J Int AIDS Soc 2009; 12(1) 3. Available from DOl: :https://doi.org/10. 1186/17582652-123.

12. WHO. HIV drug resistance fact sheet. Geneva, Switzerland: WHO; 2011. Available from: https://www.who.int/hiv/facts/WHD2011-HIVdr-fs-final.pdf. Accessed 21 Oct 2018.

13. Melsew YA, Terefe MW, Tessema GA, Ayele TA. Rate of immunological failure and its predictors among patients on highly active antiretroviral therapy at Debremarkos hospital, Northwest Ethiopia: a retrospective follow up study. J AIDS Clin Res 2013; 04(05) 211. Available from DOl:: https://doi. org/10.4172/2155-6113.1000211.

14. FHAPCO, FMoH. Management of Opportunistic Infections and Antiretroviral Treatment in Adolescents and Adults in Ethiopia. Addis Ababa, Ethiopia: FHAPCO; 2008. Available from: https://www.who.int/hiv/pub/guidelines/ ethiopia_art.pdf. Accessed 21 Oct 2018.

15. WHO. Antiretroviral therapy for HIV infection in adults and adolescents. Recommendations for a public health approach. Geneva, Switzerland: WHO; 2010. Available from: https://apps.who.int/iris/bitstream/handle/10665/ 44379/9789241599764_eng.pdf?sequence=1. Accessed 21 Oct 2018.

16. WHO. Patient monitoring guideline for HIV care and ART. Geneva: WHO; 2006. Available from: http://www.who.int/iris/handle/10665/43382. Accessed 2 May 2019.

17. Labhardt ND, Lejone T, Setoko M, Poka M, Ehmer J, Pfeiffer K, Kiuvu PZ, Lynen L. A clinical prediction score in addition to WHO criteria for antiretroviral treatment failure in resource-limited settings: experience from Lesotho. PLoS One 2012; 7(10): e47937. Available from DOl: https:/doi.org/ 10.1371/journal.pone.0047937.

18. Rajasekaran S, Jeyaseelan L, Vijila S, Gomathi C, Raja K. Predictors of failure of first-line ART in HIV infected adults; Indian experience. AIDS. 2007; 21 (Suppl 4) 547-553. Available from DOI: : https://doi.org/10.1097/01.aids. 0000279706.24428 .78$.

19. Chen RY, Westfall AO, Magavero MJ, Cloud GA, Raper JL, Chatham AG, Acosta EP, Taylor KH, Carter J, Saag MS. Duration of highly active antiretroviral therapy regimens. Clinical Infectious Disease. 2003;37(5):71422.

20. Calmy A, Ford N, Hirschel B, Reynolds SJ, Lynen L, Goemaere E, de la Vega FG, Perrin L, Rodriguez W. HIV viral load monitoring in resource-limited regions: optional or necessary? Clin Infect Dis. 2007;44(1):128-34.

21. Kantor R. Impact of HIV-1 pol diversity on drug resistance and its clinical implications. Curr Opin Infect Dis. 2006;19(6):594-06.

22. C M Kwobah , W. Mwangi A, K. Koech J, N. Simiyu G M. Siika A. Factors associated with first-line antiretroviral therapy failure amongst HIV-infected African patients: a case-control study. World Journal of AIDS 2012; 02(04) 271-278. Available from DOl:: https://doi.org/10.4236/wja.2012.24036.

23. Jaka H, Mshana S, Liwa A, Peck R, Kalluvya S. Prevalence of immunological failure and durability of first line antiretroviral therapy at Bugando hospital Mwanza, Tanzania. Tanzania Medical Journal. 2009;24(2).

24. Dragsted U, Mocroft A, Vella S, Viard J, Hansen A, Panos G, Mercy D, Machala L, Horban $\mathrm{H}$, Lundgren J. Predictors of immunological failure after initial response to highly active antiretroviral therapy in HIV-1-infected adults: a EuroSIDA study. The Journal of Infectious Disease. 2004;190(1):148-55.

25. Hosseinipour M, Kumwenda J, Weigel R, Brown L, Mzinganjira D, Mhango B, Eron J, Phiri S, VanOosterhout J. Second-line treatment in the Malawi ART program: high early mortality, but good outcomes in survivors, despite extensive drug resistance at baseline. HIV Medicine 2010; 11 510-518. Available from DOI: : https://doi.org/10.1111/j.1468-1293.2010.00825.x.

26. Keiser O, MacPhail P, Boulle A, Wood R, Schechter M, Dabis F, Sprinz E, Egger M. Accuracy of WHO CD4 cell count criteria for virological failure of antiretroviral therapy. Tropical Med Int Health 2009; 14 1220-1225. Available from DOI: : https://doi.org/10.1111/j.1365-3156.2009.02338.X. 
27. El-Khatib Z, Katzenstein D, Marrone G, Laher F, Mohapi L, Petzold M, Morris $\mathrm{L}$, Ekström AM. Adherence to drug-refill is a useful early warning Indicator of Virologic and immunologic failure among HIV patients on first-line ART in South Africa. PLoS One 2011; 6(3) e17518. Available from doi:https://doi.org/ 10.1371/journal.pone.0017518.

28. Khienprasit N, Chaiwarith R, Sirisanthana S, Supparatpinyo K. Incidence and risk factors of ART failure in treatment-naïve HIV-infected patients at Chiang Mai University Hospital, Thailand. AIDS Res Ther. 2011;8(1):42. Available from. https://doi.org/10.1186/1742-6405-8-42.

29. WHO, UNAIDS, UNICEF. Towards universal access; Scaling up priority HIV/ AIDS interventions in the health sector. Geneva, Switzerland: WHO; 2007. https://www.who.int/hiv/mediacentre/universal_access_progress_report_en. pdf?ua=1. Accessed 21 Oct 2018.

30. Liégeois F, Vella C, Eymard-Duvernay S, Sica J, Makosso L, Mouinga-Ondémé A, Delis Mongo A, Boué V, Butel C, Peeters M, Gonzalez J, Delaporte E, Rouet F. Virological failure rates and HIV-1 drug resistance patterns in patients on first-line antiretroviral treatment in semirural and rural Gabon. J Int AIDS Soc. 2012;15:17985.

31. Oyugia JH, Byakika-Tusiimeb J, Ragland K, Laeyendecker O, Mugerwa R, Kityo C, Mugyenyi P, Quinn TC, Bangsberg DR. Treatment interruptions predict resistance in HIV-positive individuals purchasing fixed-dose combination antiretroviral therapy in Kampala, Uganda. AIDS. 2007;21 (8):965-71.

\section{Publisher's Note}

Springer Nature remains neutral with regard to jurisdictional claims in published maps and institutional affiliations.

Ready to submit your research? Choose BMC and benefit from:

- fast, convenient online submission

- thorough peer review by experienced researchers in your field

- rapid publication on acceptance

- support for research data, including large and complex data types

- gold Open Access which fosters wider collaboration and increased citations

- maximum visibility for your research: over $100 \mathrm{M}$ website views per year

At $\mathrm{BMC}$, research is always in progress.

Learn more biomedcentral.com/submissions 